\title{
Article Title: The evolution of mollusc shells
}

\section{Article Type: Focus article}

\section{First author}

NAME: Carmel McDougall

ORCID: 0000-0002-2116-5651

AFFILIATION: Centre for Marine Sciences, School of Biological Sciences, The University of Queensland, Brisbane 4072, Australia

PRESENT ADDRESS: Australian Rivers Institute, Griffith University, Brisbane 4111, Australia

EMAIL ADDRESS: c.mcdougall@griffith.edu.au

CONFLICTS OF INTEREST: none

\section{Second author}

NAME: Bernard M. Degnan*

ORCID: 0000-0001-7573-8518

AFFILIATION: Centre for Marine Sciences, School of Biological Sciences, The University of Queensland, Brisbane 4072, Australia

EMAIL ADDRESS: $\underline{\text { b.degnan@uq.edu.au }}$

CONFLICTS OF INTEREST: none

\section{Graphical/Visual abstract and caption:}

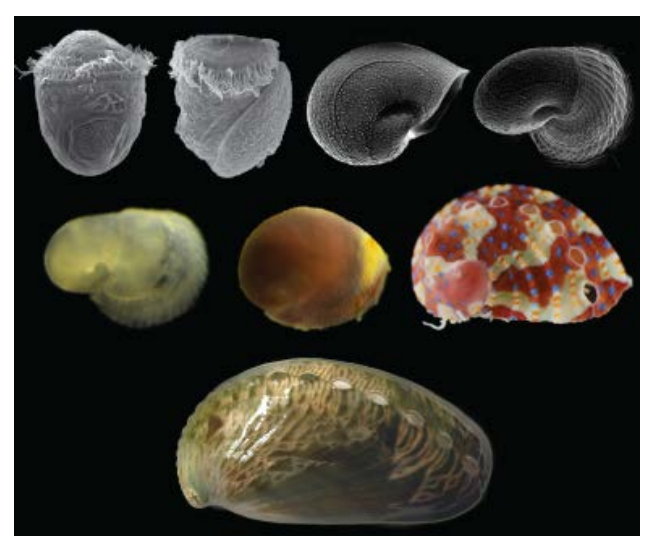

Different shell-forming gene repertoires likely explain shell evolution and diversity 


\section{Abstract}

Molluscan shells are externally fabricated by specialised epithelial cells on the dorsal mantle. Although a conserved set of regulatory genes appears to underlie specification of mantle progenitor cells, the genes that contribute to the formation of the mature shell are incredibly diverse. Recent comparative analyses of mantle transcriptomes and shell proteomes of gastropods and bivalves are consistent with shell diversity being underpinned by a rapidlyevolving mantle secretome (suite of genes expressed in the mantle that encode secreted proteins) that is the product of (i) high rates of gene co-option into and loss from the mantle gene regulatory network, and (ii) the rapid evolution of coding sequences, particular those encoding repetitive low complexity domains. Outside a few conserved genes, such as carbonic anhydrase, a so-called 'biomineralisation toolkit' has yet to be discovered. Despite this, a common suite of protein domains, which are often associated with the extracellular matrix and immunity, appear to have been independently and often uniquely co-opted into the mantle secretomes of different species. The evolvability of the mantle secretome provides a molecular explanation for the evolution and diversity of molluscan shells. These genomic processes are likely to underlie the evolution of other animal biominerals, including coral and echinoderm skeletons. 


\section{Introduction}

Biomineralisation refers to the process by which living organisms produce mineralised structures (crystalline or amorphous) from inorganic precursor ions via cellular processes ${ }^{1,2}$. Normally, the inorganic formation of analogous minerals would require extreme temperatures and/or pressures.

Biomineralising organisms, however, produce various biomolecules that interact with the mineral ions and allow these minerals to be formed under atmospheric conditions ${ }^{3}$. A distinction is often made between biologically-induced versus biologically-controlled biomineralisation. The former generally refers to sideproducts of metabolism that are dependent on environmental conditions and often not significantly different to the inorganic minerals themselves, whereas the latter are products of specialised, genetically-controlled metabolic processes, are independent of environmental conditions, and are generally distinct from their inorganic counterparts 2,4 .

Identifying the biomolecules involved in biomineralisation and understanding how they interact with mineral ions is just one active area of study. Biomineralisation research is diverse and includes investigating how the biominerals observed today evolved ${ }^{5}$, uncovering how the deployment of key biomolecules is controlled by the genome ${ }^{6}$, evaluating the effects of biomineral production on ocean biochemistry ${ }^{7}$, and predicting how increasing ocean temperatures and acidification will impact biomineralising organisms and entire ecosystems such as coral reefs ${ }^{8}$.

Molluscs have long been used as models to study biomineralisation as they produce an impressive diversity of shell types, are readily accessible, and have a rich fossil record allowing for evolutionary inferences (Fig. 1). Mollusc shells are unique in that the ontogeny of the biomaterial is recorded within the structure itself, with the oldest part (the larval and juvenile shells) typically being visible at the apex ('spire' or 'umbo') of the shell, and the newest part being at the shell edge - a useful feature for developmental biologists. Additionally, the predominant mineralising organ (the mantle ${ }^{9}$ ) is easily accessible ${ }^{1}$ and is 
separated into zones that are each responsible for secreting different layers of the shell (see below), facilitating investigations into the differences in cell biology and gene expression between these zones. From an applied perspective, the shells of many molluscs have commercial value, particularly mother-of-pearl (nacre), and this has fuelled research into the structure and formation of this shell layer. Nacre is also one of the strongest known shell layers and has been well-studied from a biomaterials perspective. Finally, molluscs produce the highest diversity of biominerals of any animal, both in terms of the mineral type deposited and the function of the materials themselves 1,4 .

\section{The evolution and diversity of biomineralised structures}

The ability to mineralise is widespread throughout life on Earth and appeared very early in evolution 1,2,10. The oldest known evidence is from stromatolites (blue-green algae that perform biologically-induced biomineralisation), dating back to 3,700 million years ago (mya) ${ }^{11}$. The first examples of biologicallycontrolled mineralisation may be the vase-shaped protist microfossils from the Chuar Group, Grand Canyon (iron-based mineralisation, 742 mya) ${ }^{12}$, or possibly the scale microfossils of the Fifteenmile Group, Yukon (812-717 mya) ${ }^{13}$. The earliest known metazoan (animal) examples are represented by Cloudina and associated forms (550 mya), which may be stem or crown group cnidarians ${ }^{14}$. Fossil remains of biomineralised structures from this time (the late Proterozoic) are scarce, suggesting that biomineralisation, at least of large-scale skeletal structures, was not widespread ${ }^{10}$. The Cambrian (543-490 mya) saw a large diversification of metazoan biomineralisation, with the first appearance of mineralised skeletons of most phyla. Further diversification within phyla occurred during the Ordovician radiation, at which time crown group members of invertebrate phyla arose and grew numerous enough to impact on marine carbonate and silica cycles 10 .

Various hypotheses have been put forward to explain the rapid diversification of biomineralisation during these periods. The Cambrian explosion occurred during a period of high $\mathrm{Ca}^{2+}$ levels in seawater, prompting speculation that 
biomineralisation (biocalcification) evolved as a means of removing toxic levels of intracellular calcium 15-17. However, this does not explain the concomitant diversification of non-calcium biomineralisation (e.g, silica-based biomineralisation) during the same period ${ }^{10}$. The increased oceanic $\mathrm{Ca}^{2+}$ is reported to be due to enhanced physical and chemical wearing of the continental crust during terminal Ediacaran and Cambrian periods, a process that also triggered the release of additional ions, including $\mathrm{Mg}^{2+}, \mathrm{HCO}_{3}^{-}, \mathrm{H}_{3} \mathrm{SiO}_{4}^{-}, \mathrm{K}^{+}$, and $\mathrm{Fe}^{3+17}$. Therefore, the observed evolutionary wave of biomineralised structures may have been trigged by the increased availability of these minerals, or perhaps the overall increase in nutrient availability facilitated an acceleration of diversification in general, with expansion of biomineralised forms just one component. It is proposed that this was further driven as a defence against increased predation pressure 10,18 .

The fossil record contains examples of numerous types of biominerals that are also found in extant species. Calcium and silica-based minerals are the most common, with aragonite and calcite (polymorphs of calcium carbonate) having the broadest distribution across taxonomic groups ${ }^{1}$. Other biominerals, including iron and magnesium-based forms, are less common and have a more restricted distribution ${ }^{1,4}$. The biomineralised structures produced are functionally diverse and include skeletons (external and internal), teeth, spines, gravity sensing organs, eye lenses and mineral storage units ${ }^{1}$. Taking into account the structures produced and the phylogenetic relationships of the organisms making them, it is likely that many are the result of independent evolutionary events, with calcium carbonate and silica biomineralisation evolving at least 28 and 8 times in eukaryotes, respectively ${ }^{10}$.

\section{What biomineralised structures do molluscs make?}

Most molluscs, although not all, produce external calcified shells. The phylum Mollusca is composed of eight extant classes that are divided into two major lineages (Fig. 2), the Conchifera (shell-bearers, including the gastropods, bivalves, scaphopods, cephalopods and monoplacophorans) and the Aculifera 
(scale-bearers, including the polyplacophorans, solenogastres and caudofoveates) ${ }^{19-21}$. As the name implies, aculiferan molluscs do not produce a single or paired shell, instead, their body is often covered in calcareous sclerites (or spicules), scales, or plates. The aculiferans tend to be more difficult to find, therefore the majority of research on molluscan biomineralisation has focussed on the shells of conchiferan species.

Although the shells and sclerites are the most obvious biomineralised structures synthesised by molluscs, members of the phylum also produce other mineralised parts including the radula (teeth), statocysts (balance organs), the operculum (trap-door for the shell aperture), the epiphragm (temporary shell-aperture trap-door for terrestrial hibernators), egg capsules, love darts (reproductive structures), gizzard plates (digestive system), and gill supports ${ }^{4}$. While the shells and sclerites are usually made of calcium carbonate - although, incredibly, there is a deep sea hydrothermal vent gastropod that coats its shell with iron sulphide 22, 23 - many of these additional structures utilise other minerals including magnetite, ferrihydrite, calcium phosphate and calcium oxalate ${ }^{4}$. The radula, in particular, of many species has strongly-bonded layers constructed of iron-based minerals ${ }^{24}$. In fact, the radula of the limpet Patella vulgata is currently the strongest biological material known to exist 25 .

\section{Ontogeny of molluscan shells and sclerites}

The shells of molluscs form early in development and display significant changes in shape, ornamentation and patterning over the life of the organism (Fig. 3) ${ }^{26}$. In conchiferans, the initial stages of shell formation occur in early embryogenesis and appear to be relatively conserved. An initial, and as yet incompletely understood, induction event causes specification of an initial cluster of biomineralising cells - the 'shell field' (reviewed in 2728,29 ). This shell field is comprised of cells that are predominately descendants of the $2 \mathrm{~d}$ micromere, with descendants of 2a and 2c (and, very rarely, 2b) also contributing in some species (28, 29 and references therein). After the induction event, the shell field invaginates and the first organic shell secretions are issued from shell gland cells 
30; at this stage, the invagination may be sealed off from the external environment 31,32 . The invaginated cells then evaginate, expand, and differentiate to eventually form the larval and then juvenile mantle 27,30 . The timing of the initial calcification of the shell appears to vary between species, but is generally very early in the development of the shell field and may occur during the initial invagination itself $27,31,32$. The larval shell is, in the first instance, amorphous in nature, at least in studied bivalves ${ }^{33}$. As the shell field expands and forms the larval mantle, so too does the shell expand so that the larva can be fully accommodated inside. This larval shell is usually unsculptured and is called protoconch I in gastropods or prodissoconch I in bivalves. In some species, a second type of larval shell, the protoconch II or prodissoconch II, is also produced - this is often more sculptured and ornate than the original shell 29. The final shell, initiated at metamorphosis, is the teloconch. In most conchiferans, the teloconch is maintained through to end of the animal's life, but it may also change a number of times in structure and pattern during juvenile growth ${ }^{26}$ (Fig. 3). Importantly, each shell is continuous with the one produced before it, so that the entire history of an animal's shell formation is visible.

In polyplacophorans (or chitons), the mantle tissue secretes both shell plates and sclerites ${ }^{34}$. Seven plate fields form within the dorsal ectoderm simultaneously prior to settlement (an eighth plate forms later), however calcified valves are not observed until after metamorphosis $27,35,36$. Sclerite formation occurs towards the lateral part of the mantle (=girdle) by secretions from a single cell; in some species, additional cells contribute secretions once sclerite formation has been initiated ${ }^{34}$. In aplacophorans, sclerite formation appears to be very similar to that in chitons, with the initial secretion occurring within an invagination of a single cell 37-39. Whether or not the cells contributing to the shell field (and, consequently, the mantle) and sclerite forming ectoderm can be considered homologous across molluscan classes is unclear - cell lineage studies suggest involvement of the $2 \mathrm{~d}$ micromere and its descendants, however additional micromeres can contribute to mineralising tissues in some taxa (reviewed in ${ }^{29}$ ). As cell lineage studies are sparse, more species need to be investigated in detail before general developmental principles can be established for these mollusc 
classes. Given the apparent ease with which calcified structures can evolve, homology of molluscan shells, plates, and sclerites should not be assumed.

\section{Molluscan shell structure}

Molluscan shells are diverse in architecture and pattern. In general, though, they are composed of multiple layers of calcium carbonate polymorphs (usually aragonite or calcite), as well as a proteinaceous outer layer, the periostracum (Fig. 4). As well as displaying different polymorphs, the layers can also have different microstructures, that is, different arrangements of individual calcium carbonate nanometric units. These arrangements are classified based on their morphology, and include prismatic, spherulitic, crossed-lamellar, homogenous and nacreous forms (see ${ }^{40}$ and ${ }^{41}$ for descriptions). Nacre, or mother-of-pearl, is arguably the best-studied microstructure. It is always aragonitic, is composed of flattened polygonal or rounded tablets arranged in layers 40,41 , and is found in several molluscan classes including bivalves, gastropods, cephalopods (Nautilus) and monoplacophorans ${ }^{42,43}$. Significant differences exist in the nacre produced by each class of mollusc. Gastropods possess columnar nacre in which the tablets are stacked on top of each other, whereas in bivalves each tablet is offset from the one below in a brick-like pattern (sheet nacre) ${ }^{44}$. Cephalopods produce nacre that is an intermediate of the two ${ }^{45}$. In addition, the tablets in gastropod, bivalve and cephalopod nacre each display different crystallographic axes ${ }^{46}$. Based on these differences it has been hypothesised that nacre may have originated several times independently $45,47,48$, therefore caution needs to be exercised when making generalisations relating to superficially similar shell layer microstructures.

Aragonite is the mineral produced most frequently for the sclerites and scales of aculiferans $38,49,50$. In aplacophorans, the sclerites can be either solid or hollow, and no layering is obvious within the structure ${ }^{38}$. The shell plates of polyplacophorans are complex. For instance, the plates of Tonicella marmorea consist of six distinct layers, each with a unique microstructure ${ }^{51}$. The structure of polyplacophoran sclerites is substantially different, with the aragonite crystals 
more closely resembling those of the abiologically formed mineral, indicating that these skeletal elements may be formed by a very different process to that of the shell plates of the same animal ${ }^{49}$.

In all the structures described above, the calcium carbonate nanometric units are in close association with an organic matrix composed of proteins, polysaccharides, and lipids ${ }^{52}$. These organic components are secreted from the underlying mantle tissue and are responsible for controlling shell formation. Recrystallisation studies, whereby demineralised matrix is placed into a solution containing saturated calcium carbonate, show that matrix from aragonitic shell layers is capable of directing aragonite precipitation in a system that otherwise produces calcite, and vice versa 53,54 . Proteomic studies have shown that the matrices of shell layers with different polymorphs contain different proteins 55 , and biochemical analyses have found that polysaccharide (e.g., chitin) ${ }^{52}$ and lipid 56 content also differs. These studies indicate that the matrix can determine both the polymorph and the microstructure formed in various shell layers. As more molluscan species are studied at the ultrastructural level, it is becoming obvious that the mantle itself is regionalised, and that unique secreted molecules originating from different zones instruct the formation of the shell layer that forms adjacent to it $26,57-60$.

\section{The molluscan shell-formation gene regulatory network}

The development of an animal is carefully orchestrated by a hierarchy of gene expression. Co-ordinating this expression are regulatory genes that act at the core of gene regulatory networks (GRNs) to precisely control the timing and location of expression of downstream 'effector' genes ${ }^{61}$. In molluscan development the initiation of the shell field is likely under the control of its own GRN; as the shell field develops into the mantle, and as shell formation is (generally) continuous from the first secretions of the shell field through to the final adult shell, the master regulators controlling the development of the shell field are thus the core regulators of the entire process of shell formation ${ }^{28}$. Subcircuits of the shell-formation GRN regulate the specification and maintenance of 
subsequent specialisations, for example, the different mantle zones responsible for the secretion of different shell layers. A number of transcription factors and signalling ligands that are involved in specification events during development of other animals have demonstrated expression in discrete zones during molluscan shell-field development, including engrailed, goosecoid, brachyury, decapentaplegic, distal-less, and various Hox genes (reviewed in ${ }^{28}$ ). However, these genes are all likely to be under the regulation of those involved in the initial induction event - a process that is not yet understood at the molecular level. We also currently know nothing about the network architecture - except that engrailed expression is not affected by knockdown of decapentaplegic 62 .

The terminal branches of the shell formation GRN include genes encoding proteins that are secreted from the mantle (the mantle secretome ${ }^{59}$ ) and are directly involved in the shell formation process ${ }^{63}$, as well as genes that control the deposition of polysaccharides and lipids in the shell. In the first models of molluscan biomineralisation it was thought that the organic matrix was comprised of relatively few components. For nacre, these components were thought to be chitin, sulfated glycoproteins, and hydrophobic proteins ${ }^{4}$. Transcriptomic and proteomic approaches have demonstrated that in fact shellbuilding appears to be complex, with at least 40-60 proteins with very different characteristics being incorporated into a single shell (likely an underestimate due to the limitations of proteomic techniques, see ${ }^{64}$ ), and it is probable that many more genes/proteins direct shell formation from within the mantle itself. Therefore, there are numerous terminal outputs of the shell formation GRN.

\section{The search for the molluscan biomineralisation toolkit}

During the development of most metazoans, the organisation of the overall body plan is specified through the action of a core set of highly conserved developmental genes, often referred to as the 'developmental' or 'genetic' toolkit 65. Alteration to the expression of these genes can cause differences in morphology on many different scales, from the conversion of one body segment to another 66 , to minute changes in the patterning of butterfly wings ${ }^{67}$. The 
possibility that biomineralisation, given its widespread distribution in animals, may also be controlled by a similar suite of conserved genes led Livingston and colleagues 68 to introduce the concept of a 'biomineralisation toolkit'. It was suggested that a common set of genetic and developmental processes may underlie skeletogenesis in divergent taxa, regardless of whether the structures produced were strictly homologous. The authors found some similarities in the early stages of the biomineralisation process in echinoderms and vertebrates, including specification of skeletogenic cell types by the transcription factors ETS and ALX. However, for the most part, proteins involved late in biomineralisation were very different in the two taxa, although there were a few examples of overlapping proteins, including members of the SPARC and cyclophilin gene families.

To date, there is no evidence for involvement of ETS and ALX homologues in the specification of the shell field or of the cells responsible for the secretion of any other biomineralised structure in molluscs. However, the developmental processes are by no means completely understood, so the existence of a widely conserved metazoan biomineralisation toolkit cannot be discounted. Similar to the case in deuterostomes, the analysis of transcriptomic and proteomic datasets from mantles and shells (representing late biomineralisation events) has found very little similarity between molluscan species ${ }^{69-72}$, although, interestingly, members of SPARC and cyclophilin gene families are expressed in the mantle in several species ${ }^{47}$. Only $15 \%$ similarity was observed between the nacreproducing secretomes of an abalone and a pearl oyster 47 , whereas only 1.1 to $7.7 \%$ similarity was detected between the proteomes of the gastropod Cepaea nemoralis and other sequenced proteomes from two gastropod and three bivalve species ${ }^{69}$. This dissimilarity has led to the speculation that these shell types may have evolved independently or that the secretome is very rapidly evolving (reviewed in ${ }^{73}$ ), and suggests that the changes observed in shell architectures may be due to the actions of a large and diverse gene set, rather than the actions of a core set of conserved developmental genes that are differentially expressed. 
Recently, Aguilera and colleagues ${ }^{63}$ made use of existing mantle transcriptomes to perform the most extensive comparative analysis of conchiferan secretomes to date. By categorising the secretomes of eight bivalve and three gastropod species into orthology groups and mapping them on to a phylogenetic tree, the authors were able to establish which gene families were likely components of the mantle secretome in the last common ancestor of bivalves and gastropods (i.e., having at least one member in a bivalve and a gastropod; 782 families in total, Fig. 5). This list includes gene families known to have other conserved functions (e.g., many nervous system-related genes), as well as genes known to be involved in biomineralisation. While these biomineralisation-related gene families could be said to represent the 'conchiferan biomineralisation toolkit', dynamic patterns of evolutionary gene loss have resulted in very few genes being present in all investigated species. Therefore the majority of these gene families do not appear to be necessary for biomineralisation.

Aguilera et al. ${ }^{63}$ found that the protein domain repertoire secreted from the mantle was highly dynamic, resulting in each of the 11 species having a unique domain profile. Nonetheless, some domains had been repeatedly and independently co-opted into mantle secretome, including carbonic anhydrase, glycoside hydrolase family 18, and polysaccharide deacetylase (Fig. 5). Arivalagan and colleagues ${ }^{74}$ performed a comparative proteomic analysis of the shells of four bivalve species with different shell architectures. They found four protein domains that were represented in each shell proteome, tyrosinase, carbonic anhydrase, chitin-binding 2, and Von Willebrand factor-A, which they propose were part of the ancestral conchiferan secretome. As mentioned above, carbonic anhydrase domains appear to have been co-opted into the mantle secretome independently, therefore it is unlikely that they were part of an ancestral toolkit; although the molluscan secretome carbonic anhydrases were found to form a single, well-supported clade in a previous study ${ }^{75}$. For the remaining domains, phylogenetic analysis has either not been performed or, in the case of tyrosinase, the secretome members fall within a very large expansion of the gene family in molluscs ${ }^{76}$. As it is unknown whether all members have biomineralisation roles, it cannot be determined whether this function is 
ancestral, and hence whether these could be considered true toolkit genes. Regardless, it appears that these four domains represent core requirements for molluscan biomineralisation.

As well as a core set of essential domains, molluscan biomineralisation may also possess a number of other common principles (reviewed in ${ }^{39}$ ). The most striking is the preponderance of sequences containing repetitive, low complexity domains (RLCDs) ${ }^{47}$, which are generally involved in aggregation or binding (reviewed in ${ }^{73}$ ). Many of these RLCDs are glycine-rich, a feature commonly observed in structural proteins that are generally involved in the production of biological materials ${ }^{77}$. Many proteins are also modular in nature, containing multiple unrelated domains within the one sequence 7875 . Both of these characteristics are likely to increase the evolvability of the secretomes via unequal crossover and replication slippage, and are likely contributors towards the rapid evolution of these genes ${ }^{73}$.

\section{Mechanisms of secretome evolution}

The extent of novelty observed in mantle secretomes and shell proteomes has been surprising, and raised questions regarding how this novelty was generated. In the large scale secretome comparison study mentioned above, Aguilera and colleagues estimated the age of gene families using a phylostratigraphic approach and mapped these on to a phylogenetic tree. The analysis revealed broad patterns of gene gain and loss in each species and lineage. Large differences between the secretomes of these species were observed, as seen in previous studies based on proteomes of fewer taxa $47,69-72$. It was found that these differences were due not only to the gain of novel genes, but also, more commonly, the differential co-option of ancient genes into secretomes in different lineages. The uniqueness of the secretomes was further reinforced by the loss of expression of these genes in a lineage-specific fashion.

Thus, genes that arose prior to bilaterian and molluscan cladogenesis, which must have originally performed functions unrelated to the mantle as they pre- 
dated the evolution of this structure, are frequently recruited into the mantle gene regulatory network. This indicates that the periphery of this gene network is highly evolvable, allowing new genes to fall under and to escape control by the core gene regulators that we can assume exist. Of all the genes found to be coopted into the secretome of conchiferan molluscs, an over-representation of genes encoding a diverse suite of domains involved in processes including protein-protein interactions, cell adhesion, recognition, immunity, extracellular matrix functions, and carbohydrate metabolism, were found (Fig. 6). Other proteomics-based studies have noted the presence of numerous proteins containing many of these domains within the shell matrix ${ }^{74,79-81}$, suggesting that this enrichment is likely to be found within genes directly involved in shell formation, rather than those that are performing non-shell related functions within the mantle. Thus, it seems that proteins with particular domains and/or functions are favoured for co-option into the shell-formation process. We currently do not know how these proteins are functioning within the shell. It is possible that the domains have retained their ancestral function, meaning that the proteins that contain them are pleiotropic (i.e., shell-forming proteins contain immune-related domains that confer an immune function to the shell itself). Alternatively, the domains may, either in their ancestral form or perhaps via modification, be directly involved in aspects of the biomineralisation process, for example, calcium binding or matrix formation. Within the organic matrix of the shell, protein-protein interactions are likely to be critically important and to directly impact the structure of the shell itself. Perhaps it is the case that the precise nature of the interactions are not important, so long as the proteins themselves are able to physically associate and to form a framework in which biomineralisation can take place. In this case, it may have been relatively easy for pre-existing proteins containing interaction domains to be recruited into the mantle secretome - any additional characteristics that these particular proteins possess can subsequently be acted on by natural selection to produce the variety of shells observed today. 
Determining whether or not two biomineralised structures are homologous is difficult, regardless of whether the comparison is being made within or between phyla. Different interpretations will likely be made depending on whether the assessment is being based on the final structure itself (i.e., in molluscs, the shells of different classes, the shells and sclerites of a single animal), the cell lineage of the cells that produce the structure, and/or the molecular processes underlying its production. Adding to the confusion is the apparent ease by which biomineralised structures can arise de novo.

Knoll ${ }^{10}$ pointed out that all cells possess the ability to regulate calcium metabolism, therefore many eukaryotes that do not possess biomineralising ancestors nonetheless possess an underlying capacity to control calcium-based mineralisations. This may explain the numerous independent evolutionary events leading towards calcium-based biomineralised structures. Understanding the evolutionary relatedness of these structures is therefore problematic. For instance, although conchiferan shells are likely to be homologous and the ontogeny of the shell-fabricating mantle appears to be shared, nacreous layers appear to have evolved independently multiple times within this developmental background. The questions that therefore arise are 1) what are the minimal molecular requirements for the generation of biomineralised structures (i.e., which proteins, protein domains, polysaccharides and lipids need to be present to promote and direct the biomineralisation process), and 2) of the extant biomineralising species, what are the shared molecular hallmarks that reflect a single evolutionary event?

This is where a nested set of comparisons may prove useful. Elucidating which features are shared between all biomineralised structures (if any), those shared between all calcium-based biomineralised structures (most probably co-opted from the general cell calcium metabolism machinery), and those shared between more closely related animals will reveal the functional requirements for each level of organisation. The analysis would also reveal the history of evolutionary events, through shared similarities that, given the high level of gene co-option and de novo gene gain, should be unique (i.e., a shared derived character, or 
novelty) ${ }^{6175}$. These core features will be integrated within the GRN governing the biomineralisation process. The core genes of this GRN are likely to be broadly conserved, should reflect the initial specification of biomineralising cells (and, thus, cell lineage), and could be said to represent the biomineralisation regulatory toolkit. Although our understanding of the number and types of genes and proteins that are involved with biomineralisation is increasing at a rapid rate due to the development of high-throughput 'omic' techniques, very little is known about the non-protein components of shells (i.e., polysaccharides and lipids). An additional challenge lies in gathering enough developmental, morphological and functional data to be able to make the required comparisons and inferences in a wide range of taxa.

\section{Conclusions}

Now that transcriptomic, proteomic and genomic data are accessible for nonmodel organisms at reasonable cost, we can expect (and have already seen) a dramatic increase in the sequence information available for molluscs, particularly in relation to the shell and mantle. With this, and the recent application of new tools for functional manipulation such as RNAi 62 , morpholinos ${ }^{76}$, and CRISPR 77 to studies of molluscan development, it is likely that we will see the elucidation of a molluscan skeletogenic GRN (in line with the already established sea urchin GRN). In parallel, functional characterisation of shell-building proteins will reveal the underlying mechanisms of shell formation, enabling us to determine which proteins (or protein characteristics) are required for each type of shell microstructure.

The integration of developmental and functional data from multiple molluscan species will enable reconstruction of the evolution of the biomineralisation process. Furthermore, the potential to sequence ancient proteomic data from fossil shells provides a tantalising opportunity to test these reconstructions 278 . Just how far back these reconstructions can be pushed remains to be seen. 


\section{Acknowledgements}

The authors would like to thank two anonymous reviewers whose comments and suggestions greatly improved the manuscript. Associated research is supported by Australian Research Council grants to BMD.

\section{References}

1. Simkiss K, Wilbur KM. Biomineralization. San Diego: Academic Press; 1989.

2. Marin F, Le Roy N, Marie B, Ramos-Silva P, Bundeleva I, Guichard N, Immel F. Metazoan calcium carbonate biomineralizations: macroevolutionary trends - challenges for the coming decade. Bull Soc geol Fr 2014, 185:217-232.

3. Veis A. Crystals and life: an introduction. Vol. 4. Chichester: John Wiley and Sons; 2010.

4. Lowenstam HA, Weiner S. On biomineralization. New York: Oxford University Press; 1989.

5. Murdock DJE, Donoghue PCJ. Evolutionary origins of animal skeletal biomineralization. Cells, Tissues, Organs 2011, 194:98-102.

6. Ettensohn CA, Kitazawa C, Cheers MS, Leonard JD, Sharma T. Gene regulatory networks and developmental plasticity in the early sea urchin embryo: alternative deployment of the skeletogenic gene regulatory network. Development 2007, 134:3077-3087.

7. Van Cappellen P. Biomineralization and Global Biogeochemical Cycles. In: Dove PM, De Yoreo JJ, Weiner S, eds. Biomineralization. Vol. 54. Washington DC: Mineralogical Society of America; 2003.

8. Ries JB, Cohen AL, McCorkle DC. Marine calcifiers exhibit mixed responses to C02-induced ocean acidification. Geology 2009, 37:1131-1134.

9. Beedham G. Observations on the mantle of the Lamellibranchia. Quart J Mic Sci 1958, 3:181-197.

10. Knoll AH. Biomineralization and evolutionary history. In: Dove PM, De Yoreo JJ, Weiner S, eds. Biomineralization. Washington: Mineralogical Society of America; 2003, 329-356.

11. Nutman AP, Bennett VC, Friend CRL, Van Kranendonk MJ, Chivas AR. Rapid emergence of life shown by discovery of 3,700-million-year-old microbial structures. Nature 2016, 537:535-538.

12. Porter SM, Knoll AH. Testate amoebae in the Neoproterozoic Era: evidence from vase-shaped microfossils in the Chuar Group, Grand Canyon. Paleobiology 2000, 26:360-385.

13. Cohen PA, Knoll AH. Scale Microfossils from the Mid-Neoproterozoic Fifteenmile Group, Yukon Territory. J Paleontology 2012, 86:775-800.

14. Germs GJB. New shelly fossils from Nama Group, South West Africa. Am J Sci 1972, 272:752-761. 
15. Brennan ST, Lowenstein TK, Horita J. Seawater chemistry and the advent of biocalcification. Geology 2004, 32:473-476.

16. Petrychenko OY, Peryt TM, Chechel EI. Early Cambrian seawater chemistry from fluid inclusions in halite from Siberian evaporites. Chem Geol 2005, 219:149-161.

17. Peters SE, Gaines RR. Formation of the 'Great Unconformity' as a trigger for the Cambrian explosion. Nature 2012, 484:363-366.

18. Bengtson S. The advent of animal skeletons. In: Bengtson S, ed. Early life on earth. Vol. 84. New York: Columbia University Press; 1994, 421-425.

19. Kocot KM, Cannon JT, Todt C, Citarella MR, Kohn AB, Meyer A, Santos SR, Schander C, Moroz LL, Lieb B, et al. Phylogenomics reveals deep molluscan relationships. Nature 2011, 477:452-456.

20. Smith SA, Wilson NG, Goetz FE, Feehery C, Andrade SCS, Rouse GW, Giribet G, Dunn CW. Resolving the evolutionary relationships of molluscs with phylogenomic tools. Nature 2011, 480:364-367.

21. Vinther J, Sperling EA, Briggs DEG, Peterson KJ. A molecular palaeobiological hypothesis for the origin of aplacophoran molluscs and their derivation from chiton-like ancestors. Proc R Soc B 2012, 279:12591268.

22. Yao H, Dao M, Imholt T, Huang J, Wheeler K, Bonilla A, Suresh S, Ortiz C. Protection mechanisms of the iron-plated armor of a deep-sea hydrothermal vent gastropod. Proc Natl Acad Sci USA 2010, 107:987-992.

23. Chen C, Linse K, Copley JT, Rogers AD. The 'scaly-foot gastropod': a new genus and species of hydrothermal vent-endemic gastropod (Neomphalina: Peltospiridae) from the Indian Ocean. J Mollus Stud 2015, 81:322-334.

24. Saunders M, Kong C, Shaw JA, Macey DJ, Clode PL. Characterization of biominerals in the radula teeth of the chiton, Acanthopleura hirtosa.J Struct Biol 2009, 167:55-61.

25. Barber AH, Lu D, Pugno NM. Extreme strength observed in limpet teeth. $J$ $R$ Soc Interface 2015, 12:20141326.

26. Jackson DJ, Wörheide G, Degnan BM. Dynamic expression of ancient and novel molluscan shell genes during ecological transitions. BMC Evol Biol 2007, 7:160.

27. Kniprath E. Ontogeny of the molluscan shell field: a review. Zool Scr 1981, 10:61-79.

28. Jackson DJ, Degnan BM. The importance of Evo-Devo to an integrated understanding of molluscan biomineralisation. J Struct Biol 2016, 192:6774.

29. Wanninger A, Wollesen T. Mollusca. In: Wanninger A, ed. Evolutionary developmental biology of invertebrates 2: Lophotrochozoa (Spiralia). Wien: Springer-Verlag; 2015.

30. Hohagen J, Jackson DJ. An ancient process in a modern mollusc: early development of the shell in Lymnaea stagnalis. BMC Dev Biol 2013, 13:27.

31. Bielefeld U, Becker W. Embryonic development of the shell in Biomphalaria glabrata (Say). Int J Dev Biol 1991, 35:121-131.

32. Kniprath E. The functional morphology of the embryonic shell gland in the conchiferous molluscs. Malacologia 1979, 18:549-552. 
33. Weiss IM, Tuross N, Addadi L, Weiner S. Mollusc larval shell formation: amorphous calcium carbonate is a precursor phase for aragonite. J Exp Zool 2002, 293:478-491.

34. Haas W. Evolution of calcareous hardparts in primitive molluscs. Malacologia 1981, 21:403-418.

35. Lord JP. Larval development, metamorphosis and early growth of the gumboot chiton Cryptochiton stelleri (Middendorf, 1847) (Polyplacophora: Mopaliidae) on the Oregon coast. J Mollus Stud 2011, 77:182-188.

36. Wanninger A, Haszprunar G. Chiton myogenesis: Perspectives for the development and evolution of larval and adult muscle systems in molluscs. J Morphol 2002, 251:103-113.

37. Woodland W. Studies in spicule formation. VI. The scleroblastic development of the spicules in some Mollusca and in one Genus of colonial ascidians. Quart J Mic Sci 1907, 51:45-53.

38. Kingsley RJ, Froelich J, Marks CB, Spicer LM, Todt C. Formation and morphology of epidermal sclerites from a deep-sea hydrothermal vent solenogaster (Helicoradomenia sp., Solenogastres, Mollusca).

Zoomorphology 2013, 132:1-9.

39. Kocot KM, McDougall C, Degnan BM. Developing perspectives on molluscan shells part 1: introduction and molecular biology. In: Saleuddin S, Mukai S, eds. Physiology of molluscs: A collection of selected reviews. Vol. 1: Apple Academic Press; 2016, 1-41.

40. Carter JC, Clark GRI. Classification and phylogenetic significance of molluscan shell microstructure. In: Bottjer DJ, Hickman CS, Ward PD, eds. Mollusks: notes for a short course. Vol. 13. Knoxville: University of Tennessee Department of Geological Sciences Studies in Geology; 1985, 50-71.

41. Chateigner D, Hedegaard C, Wenk H. Mollusc shell microstructures and crystallographic textures. J Struct Geol 2000, 22:1723-1735.

42. Marin F, Le Roy N, Marie B. The formation and mineralization of mollusk shell. Frontiers in Bioscience 2012, 4:1099-1125.

43. Checa AG, Ramírez-Rico J, González-Segura A, Sánchez-Navas A. Nacre and false nacre (foliated aragonite) in extant monoplacophorans (=Tryblidiida: Mollusca). Naturwissenschaften 2009, 96:111-122.

44. Cartwright JHE, Checa AG. The dynamics of nacre self-assembly. J R Soc Interface 2007, 4:491-504.

45. Vendrasco MJ, Checa AG, Kouchinsky AV. Shell microstructure of the early bivalve Pojetaia and the independent origin of nacre within the Mollusca. Palaeontology 2011, 54:825-850.

46. Hedegaard C, Wenk H. Microstructure and texture patterns of mollusc shells. J Mollus Stud 1998, 64:133-136.

47. Jackson DJ, McDougall C, Woodcroft B, Moase P, Rose RA, Kube M, Reinhardt R, Rokhsar DS, Montagnani C, Joubert C, et al. Parallel evolution of nacre building gene sets in molluscs. Mol Biol Evol 2010, 27:591-608.

48. Marie B, Le Roy N, Marie A, Dubost L, Milet C, Bedouet L, Becchi M, Zanella-Cléon I, Jackson D, Degnan B, et al. Nacre evolution : A proteomic approach. Mater Res Soc Symp Proc 2009, 1187:1187-KK1101-1103. 
49. Treves K, Traub W, Weiner S, Addadi L. Aragonite formation in the chiton (Mollusca) girdle. Helv Chim Acta 2003, 86:1101-1112.

50. Peebles BA, Smith AM, Spencer HG. Valve microstructure and phylomineralogy of New Zealand chitons. J Struct Biol 2017, 197:250-259.

51. Connors MJ, Ehrlich H, Hog M, Godeffroy C, Araya S, Kallai I, Gazit D, Boyce $\mathrm{M}$, Ortiz C. Three-dimensional structure of the shell plate assembly of the chiton Tonicella marmorea and its biomechanical consequences. J Struct Biol 2012, 177:314-328.

52. Furuhashi T, Schwarzinger C, Miksik I, Smrz M, Beran A. Molluscan shell evolution with review of shell calcification hypothesis. Comp Biochem Phys B 2009, 154:351-371.

53. Simkiss K. The organic matrix of the oyster shell. Comp Biochem Physiol $1965,16: 427-435$.

54. Watabe N, Wilbur KM. Influence of the organic matrix on crystal type in molluscs. Nature 1960, 188:334.

55. Marie B, Joubert C, Tayalé A, Zanella-Cléon I, Belliard C, Piquemal D, Cochennec-Laureau N, Marin F, Gueguen Y, Montagnani C. Different secretory repertoires control the biomineralization processes of prism and nacre deposition of the pearl oyster shell. Proc Natl Acad Sci USA 2012, 109:20986-20991.

56. Farre B, Dauphin Y, Brunelle A. Mollusk shell lipids. In: Bivalve biomineralisation archival potential and proxy incorporation; 2009.

57. Sleight VA, Marie B, Jackson DJ, Dyrynda EA, Marie A, Clark MS. An Antarctic molluscan biomineralisation tool-kit. Sci Rep 2016, 6:36978.

58. Jolly C, Berland S, Milet C, Borzeix S, Lopez E, Doumenc D. Zonal localization of shell matrix proteins in mantle of Haliotis tuberculata (Mollusca, Gastropoda). Mar Biotechnol 2004, 6:541-551.

59. Jackson DJ, McDougall C, Green K, Simpson F, Wörheide G, Degnan BM. A rapidly evolving secretome builds and patterns a sea shell. BMC Biol 2006, $4: 40$.

60. Sudo S, Fujikawa T, Nagakura T, Ohkubo T, Sakaguchi K, Tanaka M, Nakashima K, Takahashi T. Structures of mollusc shell framework proteins. Nature 1997, 387:563-564.

61. Davidson EH, Rast JP, Oliveri P, Ransick A, Calestani C, Yuh C-H, Minokawa T, Amore G, Hinman V, Arenas-Mena C, et al. A genomic regulatory network for development. Science 2002, 295:1669-1678.

62. Hashimoto N, Kurita Y, Wada H. Developmental role of dpp in the gastropod shell plate and co-option of the $d p p$ signaling pathway in the evolution of the operculum. Dev Biol 2012, 366:367-373.

63. Aguilera FA, McDougall C, Degnan BM. Co-option and de novo gene evolution underlie molluscan shell diversity. Mol Biol Evol 2017, 34:779792.

64. Marie B, Ramos-Silva P, Marin F, Marie A. Proteomics of CaCO3 biomineral-associated proteins: how to properly address their analysis. Proteomics 2013, 13:3109-3116.

65. Knoll AH, Carroll SB. Early animal evolution: emerging views from comparative biology and geology. Science 1999, 284:2129-2137. 
66. McGinnis W, Garber RL, Wirz J, Kuroiwa A, Gehring WJ. A homologous protein-coding sequence in Drosophila homeotic genes and its conservation in other metazoans. Cell 1984, 37:403-408.

67. Brakefield PM, French V. Butterfly wings: the evolution of development of colour patterns. BioEssays 1999, 21:391-401.

68. Livingston BT, Killian CE, Wilt F, Cameron A, Landrum MJ, Ermolaeva O, Sapojnikov V, Maglott DR, Buchanan AM, Ettensohn CA. A genome-wide analysis of biomineralization-related proteins in the sea urchin Strongylocentrotus purpuratus. Dev Biol 2006, 300:335-348.

69. Mann K, Jackson DJ. Characterization of the pigmented shell-forming proteome of the common grove snail Cepaea nemoralis. BMC Genomics 2014, 15:249.

70. Marie B, Trinkler N, Zanella-Cleon I, Guichard N, Becchi M, Paillard C, Marin F. Proteomic identification of novel proteins from the calcifying shell matrix of the manila clam Venerupis philippinarum. Mar Biotechnol 2011, 13:955-962.

71. Mann K, Edsinger-Gonzales E, Mann M. In-depth proteomic analysis of a mollusc shell: acid-soluble and acid-insoluble matrix of the limpet Lottia gigantea. Proteome Sci 2012, 10:28.

72. Marie B, Jackson DJ, Ramos-Silva P, Zanella-Cléon I, Guichard N, Marin F. The shell-forming proteome of Lottia gigantea reveals both deep conservations and lineage-specific novelties. FEBS J 2013, 280:214-232.

73. Kocot KM, Aguilera F, McDougall C, Jackson DJ, Degnan BM. Sea shell diversity and rapidly evolving secretomes: insights into the evolution of biomineralization. Front Zool 2016, 13:23.

74. Arivalagan J, Yarra T, Marie B, Sleight VA, Duvernois-Berthet E, Clark MS, Marie A, Berland S. Insights from the shell proteome: biomineralization to adaptation. Mol Biol Evol 2016.

75. Le Roy N, Jackson DJ, Marie B, Ramos-Silva P, Marin F. The evolution of metazoan $\alpha$-carbonic anhydrases and their roles in calcium carbonate biomineralization. Front Zool 2014, 11:75.

76. Aguilera F, McDougall C, Degnan BM. Evolution of the tyrosinase gene family in bivalve molluscs: independent expansion of the mantle gene repertoire. Acta Biomaterialia 2014, 10:3855-3865.

77. McDougall C, Woodcroft BJ, Degnan BM. The widespread prevalence and functional significance of silk-like structural proteins in metazoan biological materials. PLoS ONE 2016, 11:e0159128.

78. Marin F, Luquet G, Marie B, Medakovic D. Molluscan shell proteins: primary structure, origin, and evolution. Curr Top Dev Biol 2008, 80:209276.

79. Liu C, Li S, Kong J, Liu Y, Wang T, Xie L, Zhang R. In-depth proteomic analysis of shell matrix proteins of Pinctada fucata. Sci Rep 2015, 5:17269.

80. Feng D, Li Q, Yu H, Kong L, Du S. Identification of conserved proteins from diverse shell matrix proteome in Crassostrea gigas: characterization of genetic bases regulating shell formation. Sci Rep 2017, 7:45754.

81. Liao Z, Bao L-F, Fan M-H, Gao P, Wang X-X, Qin C-l, Li X-M. In-depth proteomic analysis of nacre, prism, and myostracum of Mytilus shell. $J$ Proteomics 2015, 122:26-40. 
Page 22 
Figures and legends

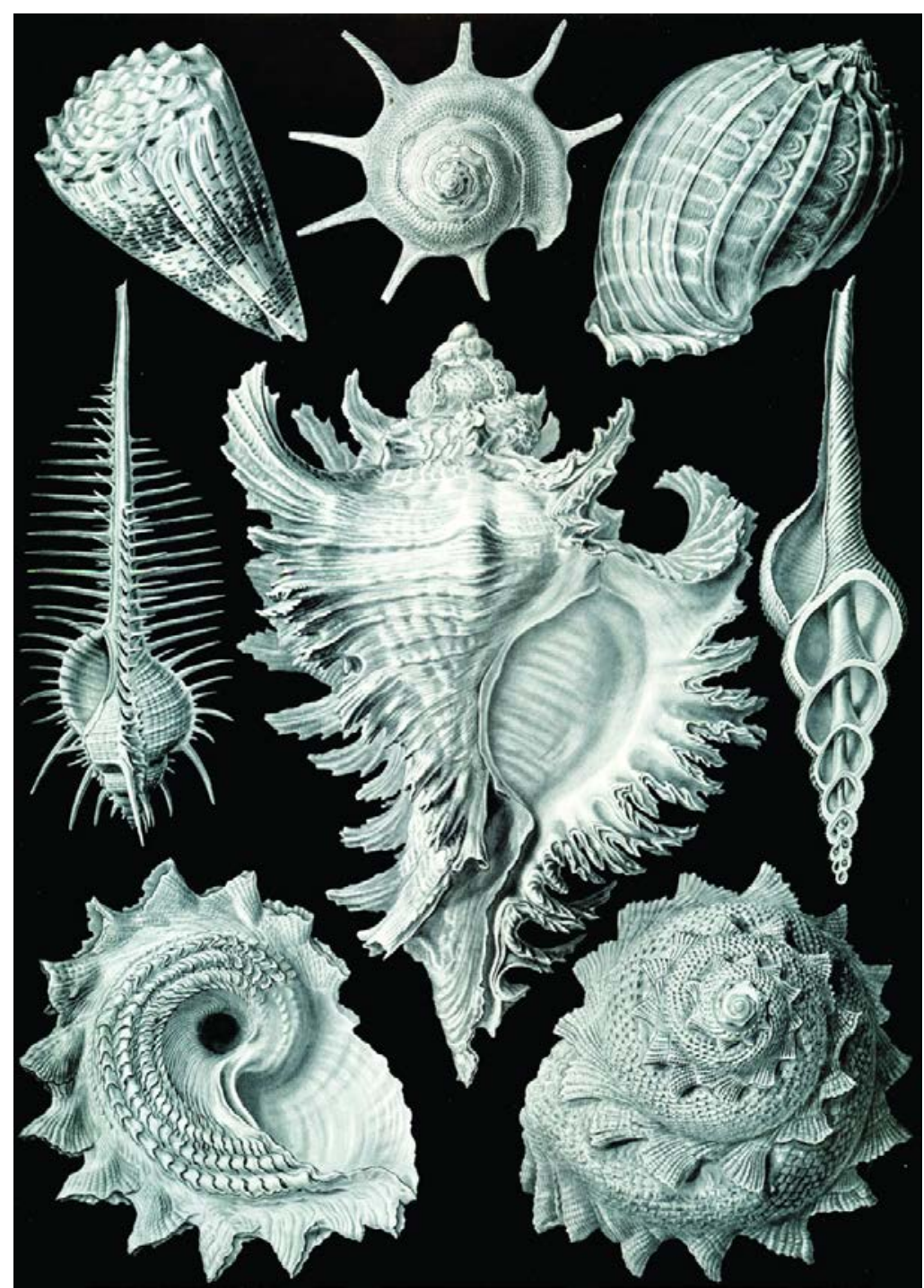

Figure 1. "Prosobranchia", a plate from Ernst Haeckel's "Kunstformen der Natur" (1904), is a beautiful depiction of the geometric beauty and diversity of sea shells. 


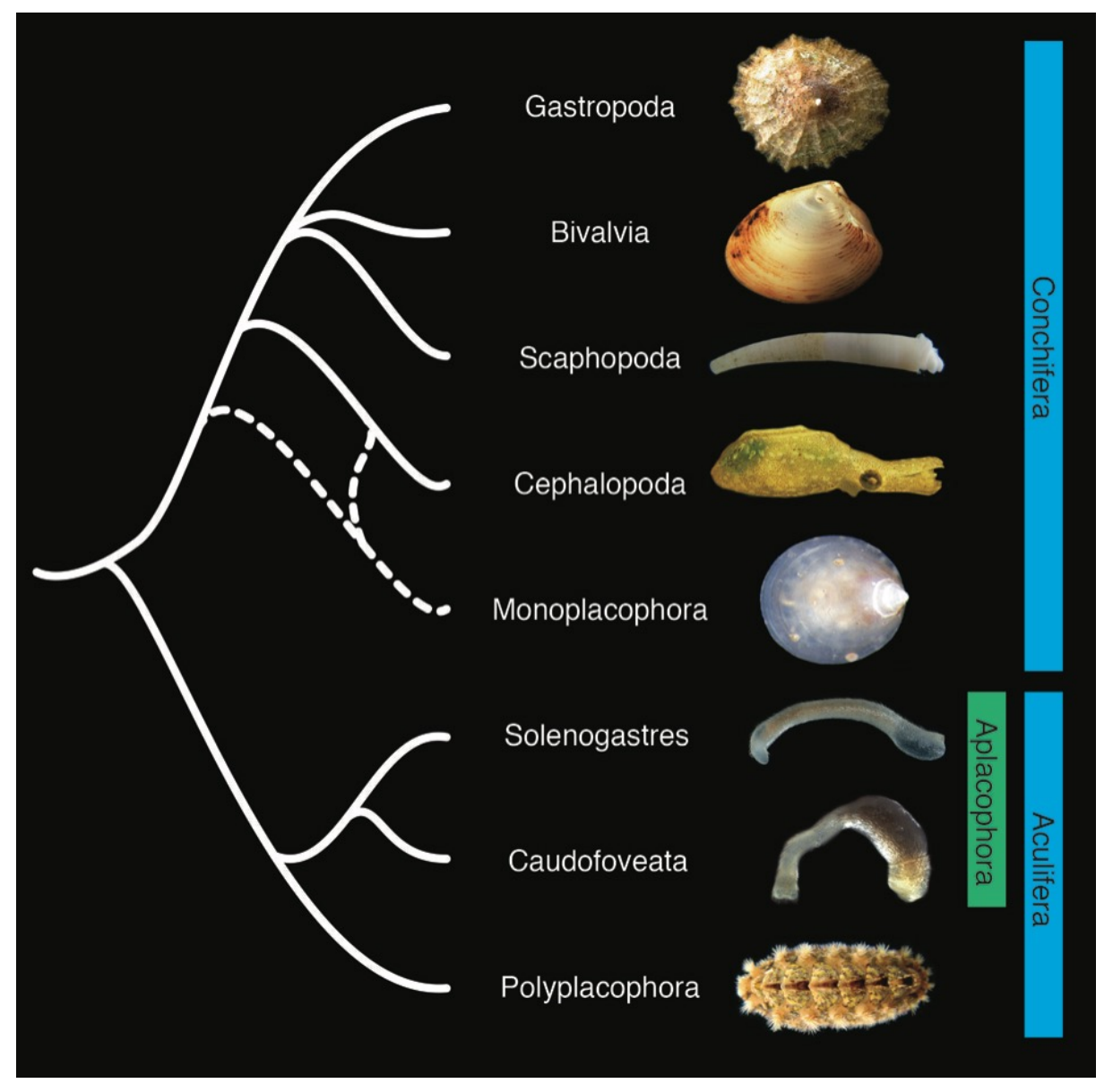

Figure 2. Current consensus of the relationships of molluscan classes from recent studies ${ }^{19-21}$. The position of Monoplacophora is unresolved. Images from 29. 


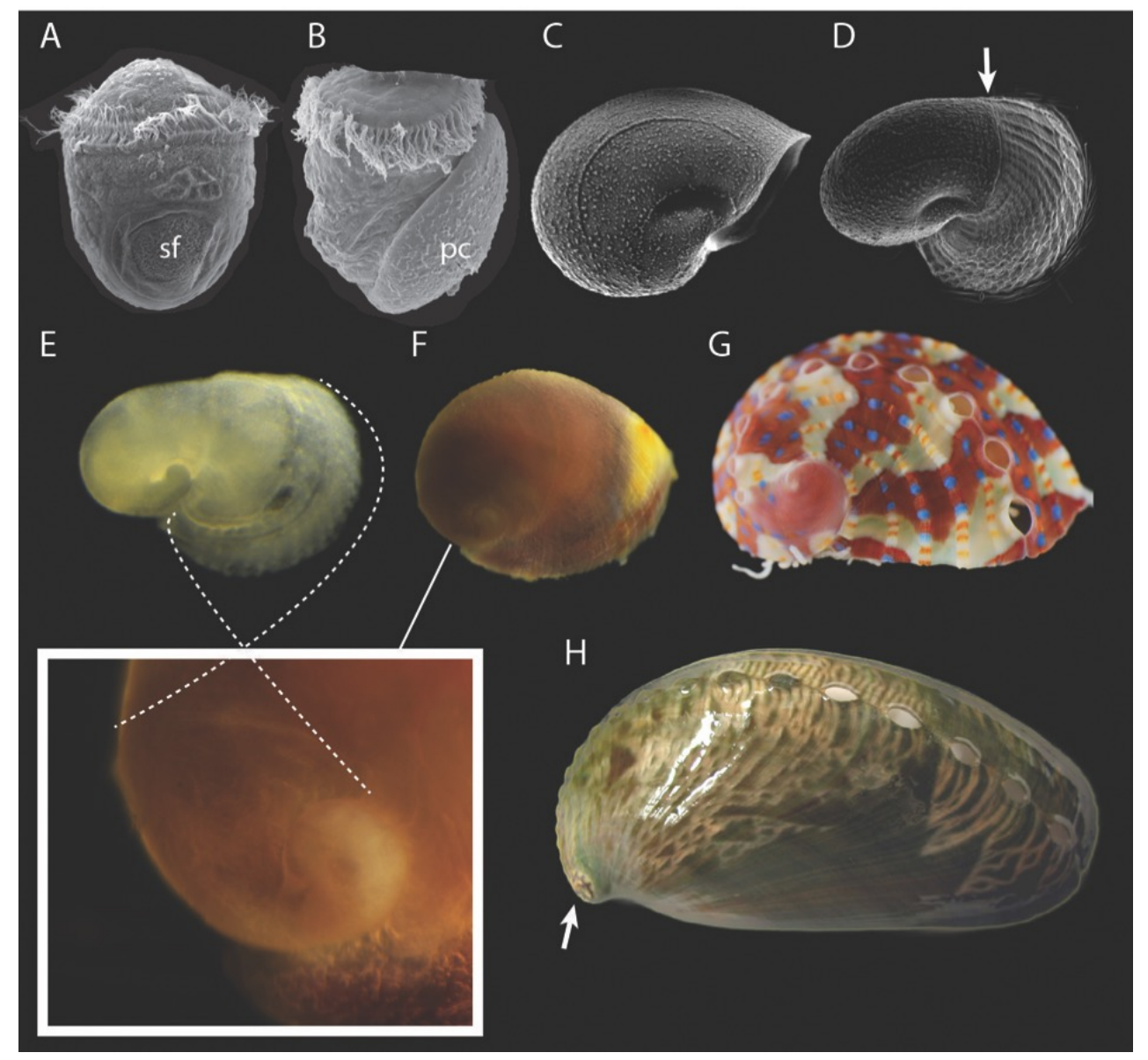

Figure 3. The development of the shell of the abalone, Haliotis asinina. A.

Scanning electron micrograph (SEM) of a trochophore larva. sf., shell field. B.

SEM of the expanding protoconch (pc) in the larva. C. SEM of the complete larval protoconch. D. SEM of early teloconch development in a recently settled juvenile. The division between the protoconch and teloconch is indicated by an arrow. E. Bright field image of a juvenile of a similar age to that in D. F. Eight week old juvenile showing the beginnings of shell patterning. G. Juvenile shell. H. Adult shell. Arrow shows the spire, where the juvenile shell is visible. Inset: higher magnification of the spire of ' $F$ '. The location of the larval and early juvenile shell is visible indicated by dotted lines. SEM images modified from ${ }^{26}$. 
A

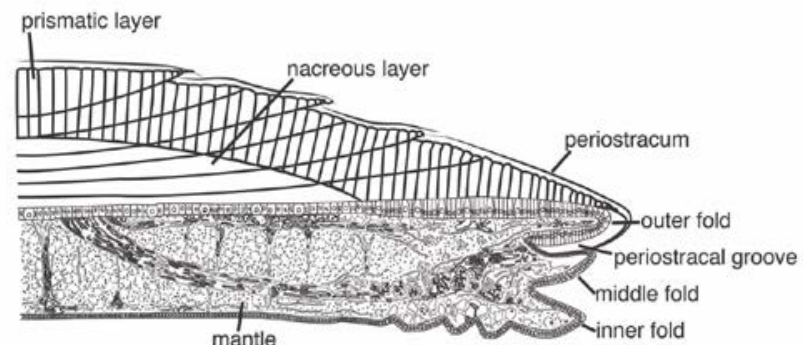

B

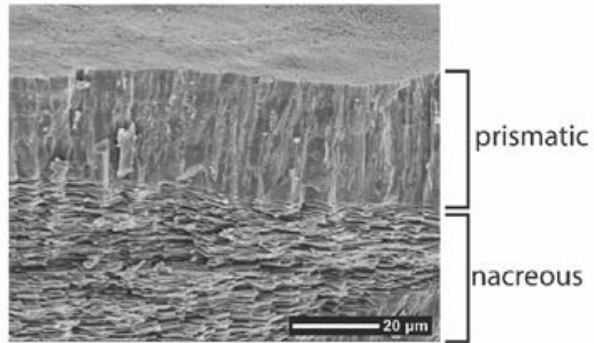

Figure 4. Shell microstructure. A. Schematic of the organisation of the molluscan shell and mantle. Redrawn from ${ }^{9}$. B. SEM of a transverse section of the juvenile shell of the abalone, Haliotis asinina. The top layer displays prismatic microstructure (P), the lower layer is columnar nacre (N). Image by Kathryn Green. 

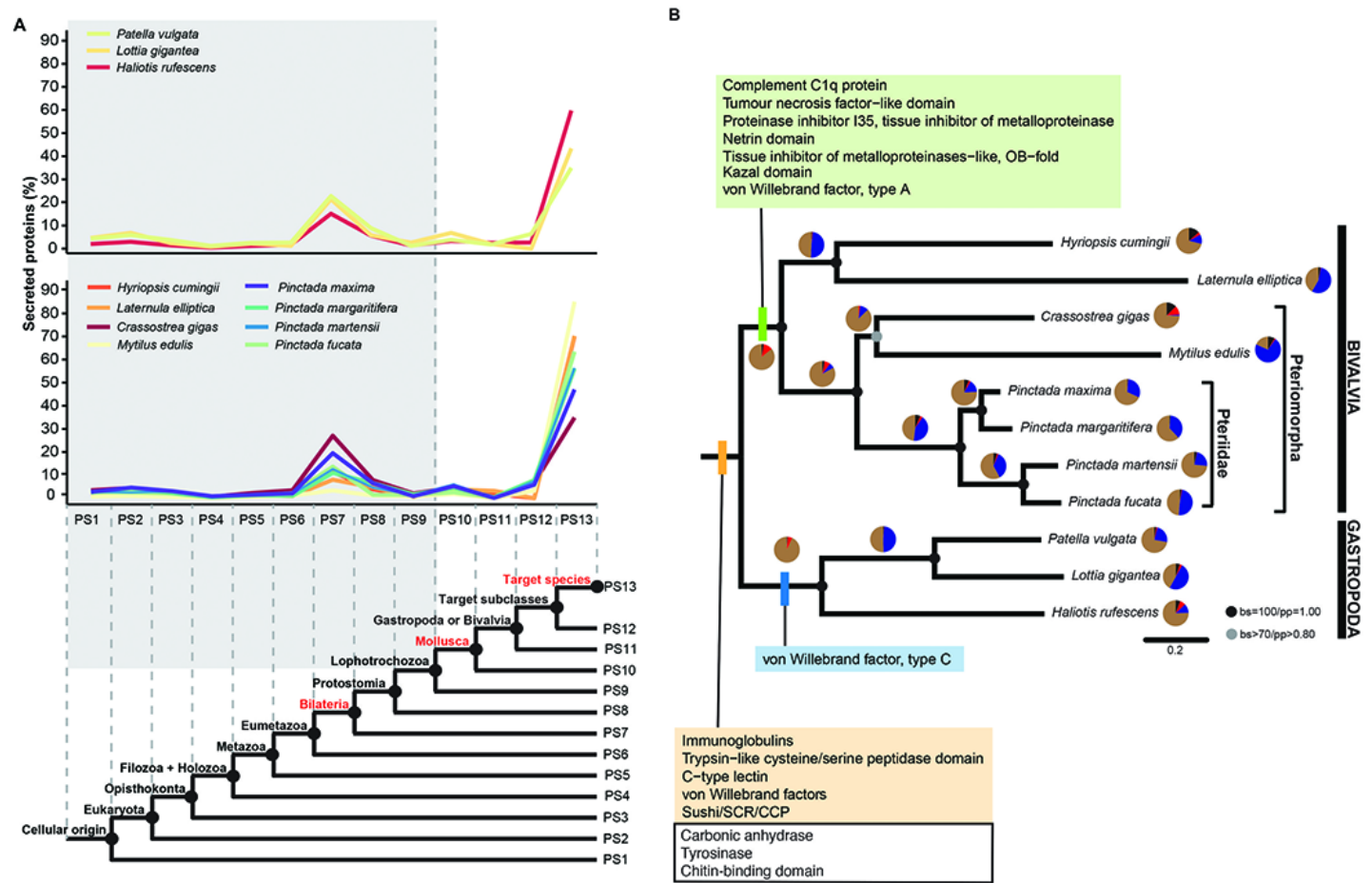

Figure 5. Evolution of the molluscan secretome. Modified from ${ }^{63}$. A. Origin of secreted mantle proteins from gastropods (top) and bivalves (middle), with phylostrata (PS1-13) depicted below. The three main evolutionary periods are indicated in red. The phylostrata indicated in grey are those that pre-date the origin of Mollusca, these proteins must therefore have been co-opted into the secretome. B. Organismal tree with pie charts showing the proportion of secretome genes that have been gained (black), co-opted (red), lost (blue) and maintained from the last common ancestor of gastropods and bivalves (BGLCA, brown). Examples of enriched domains that are inferred to have existed in BGLCA (orange box), ancestral bivalve (green box), and ancestral gastropod (blue box), are indicated. Three additional domains, carbonic anhydrase, tyrosinase, and chitin-binding domain (white box), also existed in the BGLCA secretome, these genes have also been identified in a study by Arivalagan and colleagues ${ }^{74}$. 


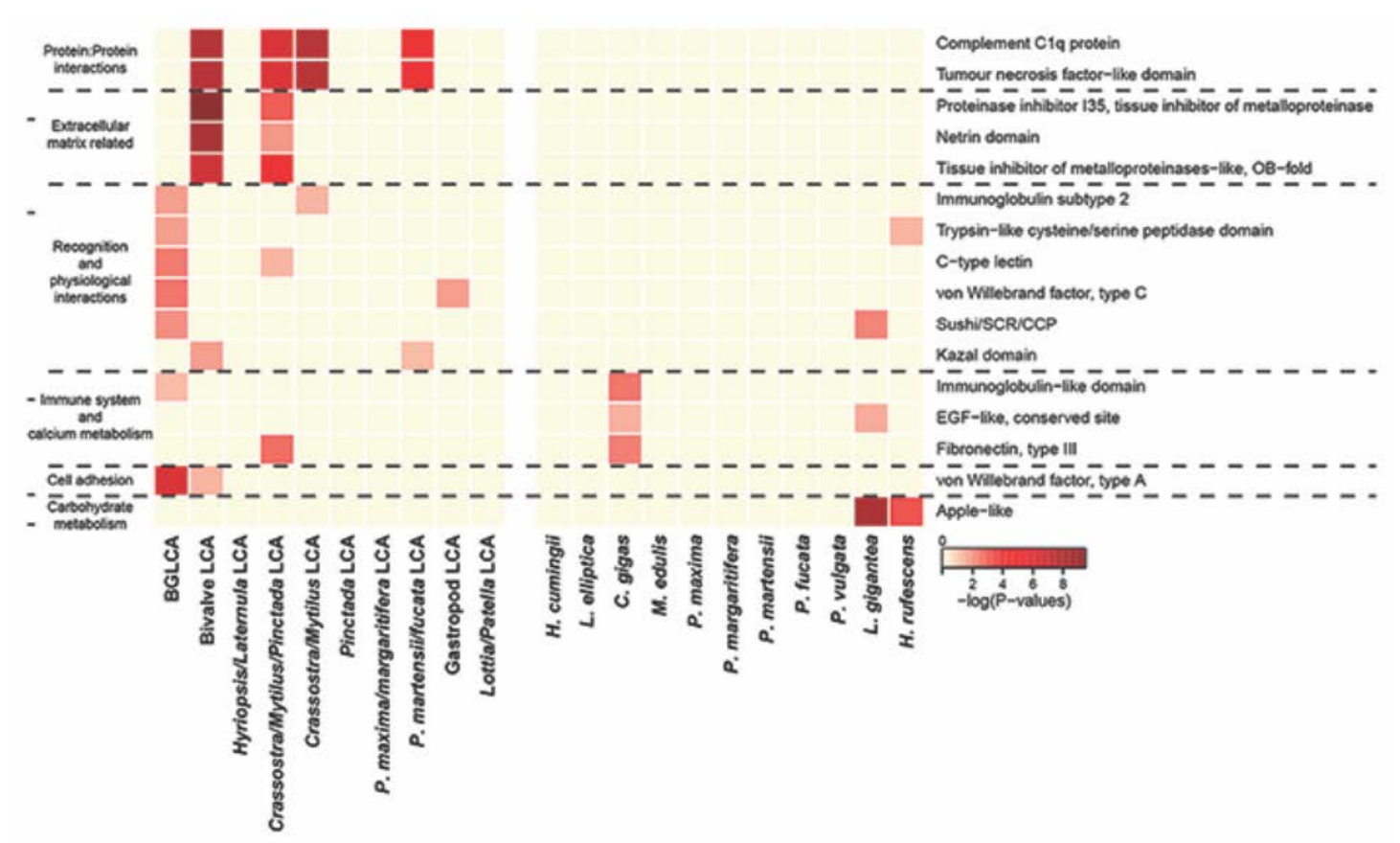

Figure 6. Enrichment of domains in co-opted gene families. Modified from ${ }^{63}$. Broad functional categories are shown on the left vertical axis of the heat map, and individual domain names are indicated on the right. Domains are represented if they are significantly enriched in newly gained secreted gene families from at least two lineages. On the horizontal axis of the heat map, ancestral lineages are depicted on the left, current species on the right (refer to the tree in Fig. 5 for the phylogenetic tree). The colour of the squares indicates the level of enrichment, only enrichments with a P-value $>0.05$ are shown. 